\title{
Syntactic and Lexical Simplification: The Impact on EFL Listening Comprehension at Low and High Language Proficiency Levels
}

\author{
Solmaz Shirzadi \\ Islamic Azad University, Shahreza Branch, Iran
}

\begin{abstract}
This study aimed at examining whether syntactic and lexical simplification affect listening comprehension at different levels. The participants were 180 female Iranian EFL students. They were learning English at an English language institute. A standardized test, namely, TOEFL was administered to choose the participants. Then the participants were divided into two groups (90 of low and 90 of high-proficiency level). The participants at high language proficiency level were randomly divided into three groups (one control group, two experimental groups). The participants at the low language proficiency level were randomly divided into three groups, too (one control group, two experimental groups). Two versions of a passage were prepared at a high language proficiency level. Two versions of a passage were prepared at a low language proficiency level, too. The obtained passages which were read by a native English teacher and recorded on a CD were played back at a normal speed rate. The participants were asked to answer the multiple-choice questions after listening to the passages. Then the answer sheets were scored. The means and the standard deviations of groups' performances were calculated. To determine whether or not there were overall significant differences between groups' performances, a t-test was separately applied within levels. The results of the t-test revealed that the groups exposed to syntactically and lexically simplified versions outperformed the other groups.
\end{abstract}

Index Terms-EFL, listening comprehension, syntactic simplification, lexical simplification, language proficiency

\section{INTRODUCTION}

Different kinds of listening can be discerned, which are classified on the basis of a number of variables, involving purpose for listening, and type of text being listened to. These variables are mixed in different shapes, and each of them needs a special strategy (Vanpatten \& Williams, 2007).Listening is a dynamic interaction of guessing approximation, expectation and idealization that naturally uses all the redundancies found in a representative discourse situation (Wang, 2010). The specific aims of the research are as follows:

1. To find out whether syntactic and lexical simplification affects listening comprehension.

2. To examine and measure the EFL students' perceived comprehension of listening texts by lexical and syntactic simplification.

The learners' success or failure in listening comprehension can be affected by many interfering factors. Among these factors, grammatical complexity of sentences and unfamiliarity of words should be taken into consideration. This research focuses on teaching listening at high school level.

Simplification as a Learning Strategy

While listening is an undeniably complex process, it requires lexicon and syntax recognition and comprehension at its most fundamental level (Koda, 2005). Lexicon forms the foundation from which a learner builds meaning at a (a) sentence, (b) paragraph, and (c) discourse level. If the listener cannot access the meaning of a critical amount of vocabulary in a text, the listening process will break down. Grabe (2002) points out that both "a large recognition vocabulary and automaticity of word recognition for most of the words in the text" are central to an EFL learner's ability to comprehend a text under normal conditions.

While the importance of vocabulary in EFL listening is well established, the methods for accommodating EFL listeners with insufficient vocabularies vary widely and many are still in formative stages. Many approaches exist that claim to facilitate the EFL listening process. Some view authentic, or unmodified texts as the best medium for EFL learners; other use discourse levels. Still others create entirely new texts that are carefully composed using a limited lexical, syntactic, or discourse levels.

Overall vocabulary knowledge is not only important in listening, but research also indicates that if a listener cannot readily access meaning for $95-98 \%$ of the specific vocabulary contained in a particular text, comprehension will be frustrated (Nation, 2001).

Lexical Simplification 
Young (1999) maintains that simplification will not necessarily aid comprehension of a text, rather the number of individual words that a learner will understand would increase. This raises again the question of measuring the relationship between number of understood words and overall comprehension of a text (Hsuch-Chao, \& Nation, 2000). Young (1999) concludes as well that simplification may overemphasize the importance of every individual word in a text, which could frustrate EFL learners, a concern that is echoed in other studies of simplification (Block, 1992).

\section{Syntactic Simplification}

Blau (1990) studied the effect of sentence structure on the EFL listening comprehension of university students. It is suggested that sentence structure which made difference in the reading comprehension study (Blau, 1982) seems to be a less dominant modification when the input is aural rather than written. Cervantes and Gainer (1992) also conducted a study to explore the effect of syntactic simplification on EFL listening comprehension. The subjects were English major freshmen and seniors in a Japanese university. They proposed that syntactic simplification is an aid to EFL listening comprehension.

Besides, two studies investigate another kind of paraphrase. No absolute effectiveness of paraphrase was found in the studies. One study of Kelch (1985) tested the effects of syntactic modification which consists of (a) paraphrase, (b) synonym, and (c) parallel syntactic structures. It was found that there was an effect only for those passages with both modifications and a slower speech rate. The other study by Pica, Young, and Doughty (1987) investigated the listening comprehension of low intermediate adult EFL learners on directions to a task presented by a native speaker. Results show that subjects' listening comprehension was facilitated when the content of the directions was repeated and rephrased in interaction. However, reduction in linguistic complexity in the premodified input was not a significant factor.

\section{Simplified Listening Texts}

One explanation for the conflicting findings in research involving modified and unmodified texts could be an interaction with the nature of the texts and the listener's proficiency levels. Following the results of other researchers, Oh (2001) questions the effect of proficiency might have on the effects of different modification. Boyle (1984) also conclude that lower proficiency levels appear to benefit more from certain type of modification has less positive effect on comprehension.

Petersen (2007) addresses the task of text simplification in the context of second language learning. A data-driven approach to simplification is proposed using a corpus of paired articles in which each original sentence does not necessarily have a corresponding simplified sentence, making it possible to learn where writers have dropped or simplified sentences. A classifier is used to select the sentences to simplify, and Siddharthan's syntactic simplification system (Siddharthan, 2006) is used to split the selected sentences.

Siddharthan proposes a syntactic simplification architecture that relies on shallow text analysis and favors time performance. The general goal of the architecture is to make text more accessible to a broader audience; it has not targeted any particular application. The system treats (a) apposition, (b) relative clauses, (c) coordination, and (d) subordination.

Max (2005) applies text simplification in the writing process by embedding an interactive text simplification system into a word processor. At the user's request, an automatic parser analyzes an individual sentence and the system applies handcrafted rewriting rules. The resulting suggested simplifications are ranked by a score of syntactic complexity and potential change of meaning. The writer then chooses his or her preferred simplification. This system ensures accurate output, but requires human intervention at every step.

\section{METHOD}

\section{Participants}

The participants of the study were 180 female Iranian EFL students. The age range was from 14 to 18 . They were learning English at an English language institute in Abadeh. After administering TOEFL as a placement test, the participants in the listening comprehension test were placed into two groups $(90$ of low and 90 of high-proficiency level).

\section{Materials}

Two versions of a listening passage were prepared for low language proficiency groups. One version was simplified lexically. The other version was simplified syntactically. Two versions of a listening passage were prepared for high language proficiency groups, too. One version was simplified lexically. The other version was simplified syntactically. The passages given to the low and high participants were chosen according to the difficulty level. The treatments are shown in the table below:

TABLE1

TREATMENTS

\begin{tabular}{|l|l|l|l|}
\hline $\begin{array}{l}\text { Language proficiency } \\
\text { level }\end{array}$ & Control group & Experimental group & Experimental group \\
\hline High & Original version & Syntactically simplified version & Lexically simplified version \\
\hline Low & Original version & Syntactically simplified version & Lexically simplified version \\
\hline
\end{tabular}




\section{Syntactic and Lexical Simplification}

Two versions of a listening passage were prepared, one version remained untouched i.e., the original one, the other was lexically simplified. This was done by identifying difficult words in the text through a simple lexicon look-up. The lexicon was "The New Oxford American Dictionary" that contains entries for difficult words. Each entry in the lexicon includes the difficult word itself, its part-of-speech, synonym, and dictionary definition. A difficult word was replaced by its synonym. If the difficult word had no synonym, then it was replaced by its corresponding dictionary definition. This simplification was done on the basis of difficulty.

To simplify a passage lexically effectively, researchers have tried to set up parameters defining the difficult words (Young, 1999). At the vocabulary level, deciding how or what to simplify depends on the definition of lexical complexity. An ordinary standard of a word's complexity has a close connection with frequency. The prevailing supposition is that more common words are naturally more familiar to listeners, and accordingly more comprehensible (Laufer, 1992).

To simplify the passage syntactically three stages were taken into consideration: (a) analysis, (b) transformation, and (c) regeneration. The passage was analyzed in the analysis stage and then passed on to the transformation stage. The transformation stage applies rules for syntactic simplification and calls the regeneration stage as a subordinate to address issues of conjunctive cohesion. When no further simplification is possible, the transformation stage carries the simplified passage to the regeneration stage, which addresses issues of anaphoric cohesion as a post-process (Siddharthan, 2006).

In order to verify the simplication technique of the study, a pilot group of participants were asked to listen to the passages and underline the sentences whose syntactic structures and vocabulary were difficult to them, and then they were asked to make a separate list of the unfamiliar words for the passages. The pilot group included a typical sample of participants resembling the study's participants. A data analysis validated the test's appropriateness. The synonyms and definitions were taken from the 2005 edition of The New Oxford American Dictionary.

\section{Procedure}

The obtained passages were read out by a native English teacher then recorded on a CD and played back at a normal speech rate. After listening to the $\mathrm{CD}$, the participants were asked to answer multiple-choice questions based on the passages. The answer sheets were then scored. An original version was given to all groups at their appropriate levels. After two weeks, an original version was given to the control groups at their appropriate levels. At the same time, two simplified versions (syntactically and lexically) were given to the experimental groups (low proficiency level) and two other simplified versions (syntactically and lexically) were given to the other experimental groups (high proficiency level) too.

\section{RESULTS}

The results of this study fell into two categories. The first dealt with the relationship between syntactic simplification and listening comprehension. The second category dealt with the relationship between lexical simplification and listening comprehension. To determine whether there was a statistically significant difference in the posttest mean scores of the experimental and control groups, a t-test was applied.

\section{Result of Lexically Simplified Listening Comprehension Test}

A t-test was run to compare the mean scores of the experimental and control groups in lexically simplified listening comprehension tests on the pretest and posttest. Table 2 shows that the mean difference was significant at the .05 level (both for low and high language proficiency levels). It could be concluded that there was a significant difference between the four groups' mean scores in lexically simplified listening comprehension pretests and posttests.

TABLE 2.

THE SUMMARY OF PAIRED SAMPLES T-TEST FOR LEXICALLY SIMPLIFIED SCORES

\begin{tabular}{|c|c|c|c|c|c|c|c|c|}
\hline \multirow{3}{*}{$\begin{array}{l}\text { Language } \\
\text { proficiency } \\
\text { Level }\end{array}$} & \multirow[t]{3}{*}{ Group } & \multicolumn{5}{|c|}{ Paired differences } & \multirow[t]{3}{*}{$\mathbf{t}$} & \multirow{3}{*}{$\begin{array}{l}\mathbf{d f}=29 \\
\text { Sig. } \\
\text { (2-tailed) }\end{array}$} \\
\hline & & \multirow[t]{2}{*}{ Mean } & \multirow[t]{2}{*}{$\begin{array}{l}\text { Std. } \\
\text { Deviation }\end{array}$} & \multirow{2}{*}{$\begin{array}{l}\text { Std. } \\
\text { Error } \\
\text { Mean } \\
\end{array}$} & \multicolumn{2}{|c|}{$\begin{array}{l}95 \% \text { Confidence interval of } \\
\text { the difference }\end{array}$} & & \\
\hline & & & & & Lower & Upper & & \\
\hline Low & Control & -0.16 & 0.59 & 0.10 & -0.38 & 0.05 & -1.54 & 0.13 \\
\hline High & Experimental & -1.83 & 3.21 & 0.58 & -3.03 & -0.63 & -3.12 & $0.00 *$ \\
\hline
\end{tabular}

\section{Result of Syntactically Simplified Listening Comprehension Test}

Again, a t-test was used to compare the mean scores of the experimental and control groups in syntactically simplified listening comprehension test. The mean difference was significant at the .05 level (for both low and high language proficiency levels). As a result, it could be concluded that syntactically simplified passages had a significant impact on the performance of the participants in the listening comprehension tests for both low and high language proficiency levels. 
TABLE 3.

THE SUMMARY OF PAIRED SAMPLES T-TEST FOR SYNTACTICALLY SIMPLIFIED SCORES

\begin{tabular}{|c|c|c|c|c|c|c|c|c|}
\hline \multirow{3}{*}{$\begin{array}{l}\text { Language } \\
\text { proficiency } \\
\text { Level }\end{array}$} & \multirow[t]{3}{*}{ Group } & \multicolumn{5}{|c|}{ Paired differences } & \multirow[t]{3}{*}{$\mathbf{t}$} & \multirow{3}{*}{$\begin{array}{l}\text { df }=29 \\
\text { Sig. } \\
\text { (2-tailed) }\end{array}$} \\
\hline & & \multirow[t]{2}{*}{ Mean } & \multirow[t]{2}{*}{$\begin{array}{l}\text { Std. } \\
\text { Deviation }\end{array}$} & \multirow{2}{*}{$\begin{array}{l}\text { Std. } \\
\text { Error } \\
\text { Mean }\end{array}$} & \multicolumn{2}{|c|}{$\begin{array}{l}95 \% \text { Confidence interval of } \\
\text { the difference }\end{array}$} & & \\
\hline & & & & & Lower & Upper & & \\
\hline Low & Control & -0.16 & 0.59 & 0.10 & -0.38 & 0.05 & -1.54 & 0.13 \\
\hline \multirow[t]{2}{*}{ High } & Experimental & -1.50 & 1.99 & 0.36 & -2.24 & -0.75 & -4.11 & $0.00^{*}$ \\
\hline & Control & -0.10 & 0.48 & 0.08 & -0.27 & 0.07 & -1.14 & 0.26 \\
\hline
\end{tabular}

\section{DISCUSSION}

This study sought to answer the following questions:

1- Does syntactic simplification have any impact on learners' listening comprehension at low and high language proficiency levels?

2- Does lexical simplification have any impact on learners' listening comprehension at low and high language proficiency levels?

The goal of this study is to see whether syntactic and lexical simplification affects listening comprehension. This may help uncover gaps and provide us with ways to encourage developing good habits of listening comprehension. This is an important question, since comprehensibility is the fundamental and necessary requirement of foreign language acquisition.

This chapter encompasses discussion and conclusions in which the investigated questions are answered and the obtained results are compared with the other researchers' investigations. Implications, limitations and suggestions for further research are also included in this chapter.

The results of the study indicate that it makes a difference to expose EFL learners to syntactically and lexically simplified listening passages. In other words, it was found that the lexical and syntactic simplification could affect the learner's performance.

Low and high proficiency language learners had a better performance when the listening passages were simplified syntactically and lexically. The results of the study showed that presenting the listening passages in simplified versions made the multiple choice tests easier for low proficiency level learners.

As for the questions posed in Chapter One, the following can be put forward.

As for question 1, it can be concluded that syntactically simplified listening passages had a significant impact on the performance of the participants in the listening comprehension tests for both low and high language proficiency levels.

As for question 2, it can be claimed that a significant impact on the participants' scores in the lexically simplified listening comprehension tests is noticed for both low and high language proficiency levels.

Results of the current study seem to support the findings of some previous researchers such as Siddharthan (2006), Petersen and Ostendorf (2007), Koda (2005), Gardener and Hansen (2007), and Crammar (2005). They proposed that syntactic and lexical simplification is an aid to EFL listening comprehension.

Still, some research has pointed out the non-significant effect of simplification on EFL listening comprehension (Blau, 1990). There seems to be inconsistency of research findings on whether simplification has an impact on EFL listening comprehension.

It seems that the difference between non-simplified version of the listening passage and the version with any kind of simplification is much more obvious than the difference between versions with various types of simplification.

\section{CONCLUSION}

The use of listening comprehension passage which is beyond the learners' comprehensibility has drawbacks. The speech used in such passages and the language is often very difficult. Anyone who has listened to passages of natural conversation knows how difficult they are to understand.

Passages labeled as authentic have not been altered to match proficiency level of language learners, and are considered by some to be an unmixed source of linguistic input for learners. One option for matching passages to the ability and range of a learner is to find so-called authentic passages appropriate for different proficiency levels. However, most unmodified passages are not labeled in terms of difficulty for EFL learners. For a listener or teacher, finding, analyzing, and cataloging so-called authentic passages would be time, and finding the right content with the right level of vocabulary may be even more problematic. On the other hand, arbitrarily choosing an authentic passage and hoping that it falls within the ability range of an EFL learner may be especially difficult (Tweissi, 1998).

Linguistic modification is a common occurrence in foreign language communication, as demonstrated in almost any case of a native English speaker interacting with a beginning English learner. Slow rate of speaking, emphasis of key words, use of common vocabulary and repetition are all modifications to aid comprehension. These adaptations are all ways that English learners' negotiations of language can be facilitated, and they are performed almost instinctively by 
native speakers. Spoken language can be negotiated between the speaker and receiver as the language is generated, and the speaker can adapt the message according to the perception of the receiver's understanding and proficiency (Hatch, 1983; Krashen, 1983).

The findings of this study indicate that difficult vocabulary and complex language are variables affecting listening comprehension. Teachers and lecturers should therefore attempt to simplify their language to enhance comprehension. It should not be inferred from this investigation that over simplification can be recommended but rather that they would become more aware of the problems encountered by their students in academic listening comprehension and would be able to assist them to overcome their difficulties.

\section{A. Implications}

This study has implications for selection of suitable listening materials in language classrooms. Teachers should pay attention when selecting listening passages to ensure that learners encounter materials that are at a suitable level of difficulty. Our suggestion is that teachers and educational specialists should consider the learners' linguistic proficiency. With respect to the role of the learner's competence in the target language, it should be kept in mind that exposure to more comprehensible listening materials might evolve the learners' linguistic knowledge.

It is clearly desirable to use syntactically and lexically simplified input at different points in a language course. Simplified input is useful for presenting specific language items economically and effectively. The course designer has a total control over it, and can provide just the linguistic elements and contextual back up he/she wishes. If students are exposed to unsimplified input, they are unlikely to meet all the high frequency items they need to learn. Elementary students faced with unsimplified input that is not very carefully selected may find it so difficult that they become unable to understand unfamiliar lexis and syntactic complexity.

\section{B. Limitation of the Study}

One of the limitations of this study is the phrasal verbs used as replacements for the target words. The meaning of an entire phrasal verb often differs from the meaning of the base word alone. Thus, the phrasal verbs used as replacements for the off-list words may not have been any familiar to the participants than the original words, and they may have affected the comprehension scores.

In addition, there seems to be some relationship between the type of comprehension task and the effect of syntactic and lexical simplification on learners' listening comprehension performance. The comprehension task applied in this study is multiple choice questions. The study by Cervantes and Gainer (1992) used a cloze test to measure subjects' listening comprehension. According to Chaudron's (1985) scheme, a cloze test requires a lower degree of speech comprehension than multiple-choice questions do. Thus, it seems that syntactic and lexical simplification can improve the performance in tasks requiring less comprehension, instead of those more complicated listening tasks.

\section{Suggestions for Further Research}

The findings of the study offer fruitful avenues for future research. While research in lexical simplification is becoming more established and many lexically simplified materials exist, the possible benefits of lexical elaboration have largely been ignored. Understanding how learners process lexical elaboration might provide useful insight into the use of this tool in the future.

The use of frequency lists is an invaluable tool in organizing and evaluating different registers of language. However dependence on such lists should be carefully considered. Lists should be evaluated for actual occurrence in current language, polysemy, and other measures. While this may be a discouraging task, it may be a necessary prerequisite before confidence can be obtained in using the lists to define relative text difficulty. A standard measurement for frequency and difficulty for vocabulary might then be established.

This study was done with the participants studying at an English private school, another research can be conducted with the subjects at university level. In this experiment the materials used were of a text type. Some other experiments can be accomplished using simplified dialogs. At present, the lines of reasoning that would establish a causal link between simplification and learning outcome has received some supporting evidence for the first step in the argument, that is, speech simplification improves comprehension. The second step, the impact of comprehension on learners' syntax and lexicon ability is untested.

\section{REFERENCES}

[1] Blau, E. K. (1982). The effect of syntax on readability for ESL students in Puerto Rico. TESOL Quarterly, 16(3), 517-528.

[2] Blau, E. K. (1990). The effect of syntax, speed, and pauses on listening comprehension. TESOL Quarterly, 24, 746-753.

[3] Block, E. (1992). See how they read: Comprehension monitoring of L1 and L2 readers. TESOL Quarterly 26(2), 319-343.

[4] Boyle, J. P. (1984). Factors affecting listening comprehension. ELT Journal, 38(1), 34-38.

[5] Candido Junior, A., Maziero, E., Gasperin, C., Pardo, T.A.S., Specia, L., \& Aluisio, S. M. (2009). Supporting the adaptation of texts for poor literacy readers: A text simplification editor for Brazilian Portuguese. Retrieved March 12, 2011, from http://www.cs.rochester.edu/ tetreaul/bea4/Candido-BEA4.pdf.

[6] Cervantes, R., \& Gainer. G. (1992). The effects of syntactic simplification and repetition on listening comprehension. TESOL Quarterly, 26, 767- 770. 
[7] Chaudron, C. (1985). Comprehension, comprehensibility, and learning in the second language classroom. Studies in Second Language Acquisition, 7, 216-232.

[8] Cramer, E. (2005). The effects of lexical simplification on ESL learners' perceived reading comprehension. Unpublished master's thesis, Bringham Young University, Provo, UT.

[9] Crystal, D. (1992). An Encyclopedic Dictionary of Language and Languages. Oxford: Blackwell Publishers.

[10] Gardener, D., \& Hansen, E. (2007). Effects of lexical simplification during unaided reading of English informational texts. TESL Reporter, 40(2), 27-59.

[11] Grabe, W. (2002). Reading in a second language. In R. B. Kaplan (Ed.), The Oxford Handbook of Applied Linguistics (pp. 4959). Oxford: Oxford University.

[12] Hatch, E. (1983). Psycholinguistics: A second language perspective. Rowley, Mass.: Newbury House.

[13] Kelch, K. (1985). Modified input as an aid to comprehension. Studies in Second Language Acquisition, 7, 81-89.

[14] Koda, K. (2005). Insights into second language acquisition: A cross-linguistic approach. Cambridge: Cambridge University Press.

[15] Krashen, S. (1983). The natural approach: Language acquisition in the classroom. New York: Pergamon Press.

[16] Max, A. (2005). Simplification interactive pour la production de texts adaptés aux personnes souffrant de troubles de la compréhension. Proceedings of the Traitment Automatique des Langues Naturelles(TALN).

[17] McKean, E. (Ed.). (2005). The New Oxford American Dictionary (2th ed.). Oxford: Oxford University Press.

[18] Nation, I. S. P. (2001). Learning Vocabulary in Another Language. Cambridge: Cambridge University Press.

[19] Oh, S. Y. (2001). Two types of input modification and EFL reading comprehension: Simplification versus elaboration. TESOL Quarterly, 35, 69-96.

[20] Petersen, S. E. (2007). Natural language processing tools for reading level assessment and text simplification for bilingual education. Doctorial dissertation, University of Washington-U. S. A.

[21] Petersen, S. E., \& Ostendorf, M. (2007). Text simplification for language learners: A corpus analysis. Proceeding of the Speech and Language Technology for Education Workshop, pp. 69-72.

[22] Pica, I., Young, R., \& Doughty, D. (1987). The impact of interaction on comprehension. TESOL Quarterly, 21, $737-758$.

[23] Reading comprehension-short stories. $\quad$ (n.d.). Retrieved March 12, 2011, from http://www.Englishforeveryone.org/Topics/Reading\%20Comprehension.html.

[24] Siddharthan, A. (2006). Syntactic simplification and text cohesion. Unpublished doctorial dissertation, University of Cambridge-UK.

[25] Tweissi, A. (1998). The effects of the amount and type of simplification on foreign language reading comprehension. Reading in a Foreign Language, 11, 191-206.

[26] VanPatten, B., \& Williams, J. (2007). Introduction. In B. VanPatten \& J. Wiliams (Eds.), Theories in SLA. Mahwah, NJ: Lawrence Erlbaum Associates.

[27] Wang, X. (2010). Features of input of second language acquisition. Retrieved March 12, 2011, from http://www.psyling.psy.cmu.edu/papers/years/1997/degroot.pdf.

[28] Young, D. (1999). Linguistic simplification of SL reading material: Effective instructional practice? The Modern Language Journal, 83, 350-366.

Solmaz Shirzadi holds an M.A. degree in TEFL from Azad University of Shahreza and has taught EFL in different institutes in Esfahan- Iran. 